Journal of Engineering and Applied Sciences 7 (1): 108-112, 2012

ISSN: 1816-949X

(C) Medwell Journals, 2012

\title{
Compressive Strength and Crack Propagation of Cement Composites Reinforced Coconut Fibre
}

\author{
Alida Abdullah, Shamsul Baharin Jamaludin, Mazlee Mohd Noor and Kamarudin Hussin \\ School of Materials Engineering, Universiti Malaysia Perlis, \\ Kompleks Pusat Pengajian Jejawi 2, 02600 Arau, Perlis, Malaysia
}

\begin{abstract}
This study presents the compressive strength and crack propagation of cement composites reinforced coconut fibre. The development of cement composites in this research were done by substituting coconut fibre to the portion of sand based on the ratio of cement to sand. Cement composites were mixed with $3,6,9,12,15 \mathrm{wt}$. \% of coconut fibre and amount of water per cement ratio was fixed at 0.55 . They were then cured in water for 7,14 and 28 days of curing. The result obtained that the cement composite with 9 wt. $\%$ of coconut fibre gives highest compressive strength and the crack propagation is controlled by coconut fibre addition.
\end{abstract}

Key words: Compressive strength, crack propagation, cement composite, coconut fibre, water, Malaysia

\section{INTRODUCTION}

In Malaysia, there have many agricultural waste products such as palm ash, coconut fibre, rice husk and oil palm frond fibre. If the waste can not be disposed properly, it will lead to social and environmental problem. At present, there are many researches focus on natural fibres addition in construction materials field such as development of cement composites (Palomar et al., 1997; Khedari et al., 2005; Asasutjarit et al., 2009). Most of them focused on physical and mechanical properties of cement composites. None of them are focusing on crack profile after the sample was loaded during compression stress test. This crack profile study is important in order to relate the role of fibre in strengthening cement composite. In this study, coconut fibre is added to substitute the portion of sand in the ratio of cement to sand. This proposed design mixture was aimed to reduce the use of sand in order to preserve our natural resources. The selection of coconut fibre in this study is a good effort in order to reduce a bulk of coconut fibre waste in Malaysia. According to a survey that is conducted by Ministry of Agricultural Malaysia (Hashim, 2005), there are about 156,000 ha of coconut plantation in Peninsular Malaysia. There will be a huge amount of waste with these huge plantations. Recycling the waste material is one of the best methods with the intention of treating the agricultural waste. Coconut fibre is the most interesting fibre as it has the lowest thermal conductivity and bulk density. Some researchers have reported that the addition of coconut fibre reduced the thermal conductivity of the composite samples (Asasutjarit et al., 2007; Khedari et al., 2001).

\section{MATERIALS AND METHODS}

In this research, there are five steps have been done to produce composite samples. The 1st step is to prepare the raw materials which are coconut fibre, sand, cement and water. The 2nd step is to weight all of the raw materials. As for this research, the study has focused on six different ratios of cement to sand. These raw materials were then mixed together in a mechanical mixer to obtain a homogenous mixing of cement composite's sample. The 4th step is to transfer the uniform wet mix to an empty mould according to the mould's size to make composite. The size of mould is depending on the test that will be carried out for the composites. The final step is to cure the composite in water for 7,14 and 28 days. In this curing process, the composite get the initial strength. Once the samples were taken out from the curing tank, the testing for mechanical and physical properties of cement composite was done. Figure 1 shows the flow for the

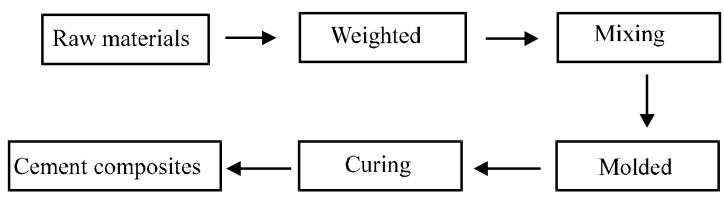

Fig. 1: Flow chart of the development of cement composite reinforced coconut fibre

Corresponding Author: Alida Abdullah, School of Materials Engineering, Universiti Malaysia Perlis,

Kompleks Pusat Pengajian Jejawi 2,02600 Arau, Perlis, Malaysia 
Table 1: Proportions of cement composites

\begin{tabular}{lccc}
\hline Samples & Cement:Sand & Water/cement & Coconut fibre (wt. \%) \\
\hline 0 & $1: 1.00$ & 0.55 & 0 \\
3 & $1: 0.97$ & 0.55 & 3 \\
6 & $1: 0.94$ & 0.55 & 6 \\
9 & $1: 0.91$ & 0.55 & 9 \\
12 & $1: 0.87$ & 0.55 & 12 \\
15 & $1: 0.84$ & 0.55 & 15 \\
\hline
\end{tabular}

developments of cement composites reinforced coconut fibre. As for Table 1, the study has focused on six different ratios of cement to sand and then coconut fibre was added to the mixture replacing the portion of sand.

\section{RESULTS AND DISCUSSION}

Morphology: The micrograph for coconut fibre observed under Scanning Electron Microscope (SEM) was shown in Fig. 2a, b. From the Fig. 2a, the fibre were observed using low magnification $(100 \times)$ and it shows that fibre surface is covered with protrusions and also some small voids and long crack.

Compressive strength of cement composite: Compression test in this study has been done by using Gotech Universal Testing Machine (UTM). By referring to the British Standard of BS5669 Part 1, the sample with size of $160 \times 40 \times 40 \mathrm{~mm}$ was prepared for the compression test. Five samples for each different ratio were tested and the average results were recorded.

Table 2 shows all the result of compressive strength for cement composites reinforced coconut fibre for 7,14 and 28 days. After 7 days of curing, it was indicated that the composite cement reinforced with 9 wt. \% of coconut fibre gives the highest compressive strength which is $31.08 \mathrm{MPa}$ and the lowest compressive strength is $22.47 \mathrm{MPa}$ given by the composite cement reinforced with 15 wt. $\%$ of coconut fibre.

The compressive strength of the composites after 14 days of curing has similar trend in which the composite cement reinforced with 9 wt. \% of coconut fibre represents the highest value of compressive strength (39.08 MPa). Again, composite cement with 15 wt. \% content of coconut fibre gives lowest value of compressive strength (25.48 MPa). The result of compressive strength of the composites after 28 days of curing also shows composite cement reinforced with 9 wt. $\%$ of coconut fibre still gives the highest value of compressive strength which is 43.84 MPa and the lowest value is $26.04 \mathrm{MPa}$ given by the composite reinforced with 15 wt. $\%$ of coconut fibre. From all the compressive strength results after 7,14 and 28 days of curing, it can be concluded that the compressive strength increased with increasing amount of coconut fibre. The highest compressive strength (43.84 MPa)
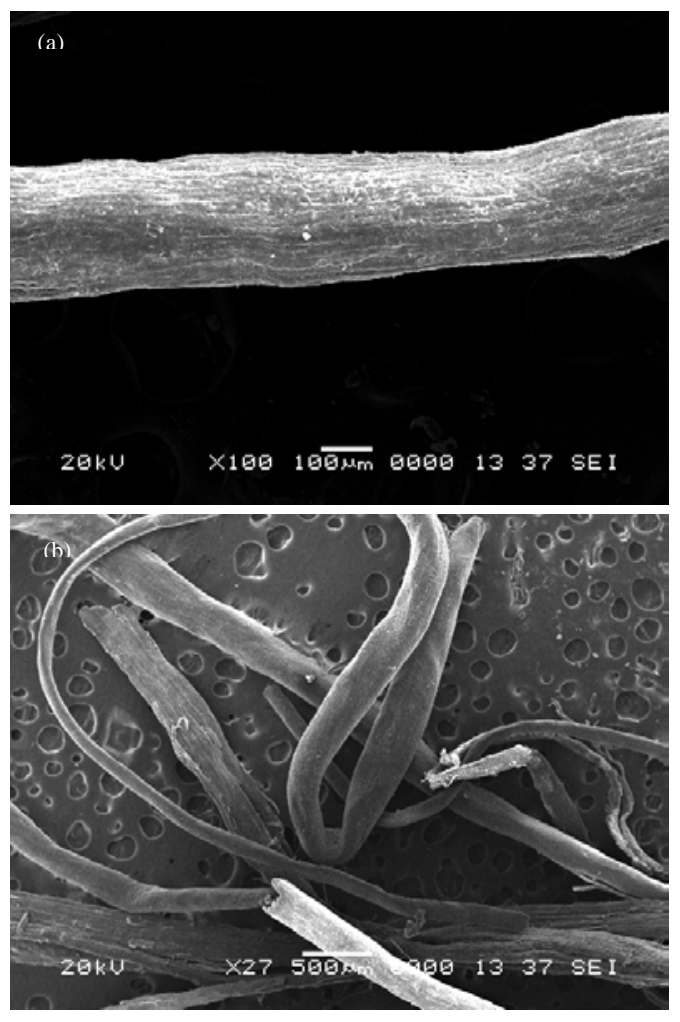

Fig. 2: a) SEM image of coconut fibre at $\times 100$; b) SEM image of coconut fibre at $\times 500$

recorded is for the composite cement reinforced with $9 \mathrm{wt}$. $\%$ of coconut fibre after 28 days of curing. The lowest compressive strength $(22.47 \mathrm{MPa})$ is given by the composite reinforced with $15 \mathrm{wt}$. \% of coconut fibre after 7 days of curing. Day of curing also influences the compressive strength of the samples. Compressive strength for 28 days of curing is $>14$ and 7 days for all of six ratios. In this study when the fibre content is increased until its optimum value, the mixing process becomes more compatible and workable.

In this research, the optimum content of coconut fibre is 9 wt. \%. However, further increased in the content of coconut fibre $>9$ wt. $\%$, it shows the decreased in compressive strength. This due to the lack of water for composites with both mixing ratio (12 and $15 \mathrm{wt} \%$ ) causes the mixing is not workable and difficult to mix homogenously. In fact if the fibre is stiff because of less water in mixture then the packing of the fibre becomes difficult at high fibre content and voids are introduced into the product. In this research when the amount of coconut fibre is fixed at 3 wt. $\%$, workability and uniformity of the mixture is difficult to achieve at 0.55 of water per cement ratio. Excessive bleeding was found 
Table 2: Compressive strength of cement composites for 7, 14 and 28 days of curing with different portion of coconut fibre

\begin{tabular}{lcccccc}
\hline Days of curing & 0 (wt. \%, MPA) & 3 (wt. \%, MPA) & 6 (wt. \%, MPA) & 9 (wt. \%, MPA) & 12 (wt. \%, MPA) & 15 (wt. \%, MPA) \\
\hline 7 & 28.59 & 27.34 & 29.63 & 31.08 & 24.48 & 22.47 \\
14 & 31.23 & 30.09 & 31.36 & 39.65 & 25.78 & 25.48 \\
28 & 41.19 & 33.73 & 38.54 & 43.84 & 27.05 & 26.04 \\
\hline
\end{tabular}

Table 3: Density of cement composites for 7,14 and 28 days of curing with different portion of coconut fibre

\begin{tabular}{|c|c|c|c|c|c|c|}
\hline Days of curing & 0 (wt. $\%, \mathrm{~kg} \mathrm{~m}^{-3}$ ) & 3 (wt. $\left.\%, \mathrm{~kg} \mathrm{~m}^{-3}\right)$ & $6\left(\right.$ wt. $\left.\%, \mathrm{~kg} \mathrm{~m}^{-3}\right)$ & 9 (wt. \%, $\mathrm{kg} \mathrm{m}^{-3}$ ) & 12 (wt. $\%, \mathrm{~kg} \mathrm{~m}^{-3}$ ) & 15 (wt. $\%, \mathrm{~kg} \mathrm{~m}^{-3}$ ) \\
\hline 7 & 2243 & 2125 & 2080 & 2035 & 1930 & 1893 \\
\hline 14 & 2233 & 2088 & 2030 & 2025 & 1895 & 1875 \\
\hline 28 & 2193 & 2055 & 2025 & 1955 & 1888 & 1845 \\
\hline
\end{tabular}

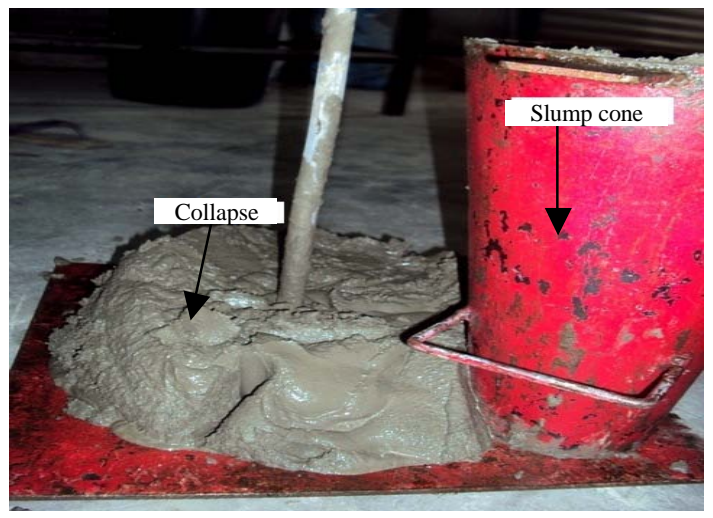

Fig. 3: The Slump test for cement composite with 3 wt. \% of coconut fibre

during the production process. It means that the mixing ratio is not workable and contributed to lowest compressive strength. The concept found here is almost similar in concrete. The increasing of water cement ratio beyond the minimum required for workability for some mix design will decrease the compressive strength of the concrete (Askeland and Phule, 2006; Ahmad and Nurazuwa, 2008). Figure 3 shows the slump test for cement composite with 3 wt. $\%$ of coconut fibre. Slump test measures the consistency or the wetness of the mix. Among all of three types of various shapes of slump test which are true slump, shear slump and or collapse, Fig. 3 shows that the slump type is collapse slump. A collapse slump is an indication of too wet a mix or that it is a high workability mix.

Density of cement composites: The density test was carried out for cement composites with the size of $100 \times 100 \times 40 \mathrm{~mm}$. Three samples were tested for each different ratios and the average value was recorded. The density value for cement composites for 7, 14 and 28 days are shown in Table 3. From Table 3 , the density of cement composite for 7 days of curing has showed that the value of density has decreased with increasing weight percent of coconut fibre. The composite cement reinforced with 15 wt. $\%$ of coconut fibre has the lowest value which is $1893 \mathrm{~kg} \mathrm{~m}^{-3}$ whereas the reference sample indicated the highest value about $2243 \mathrm{~kg} \mathrm{~m}^{-3}$. Density values of the composites after 14 days of curing are also shown in Table 3. From Table 3, it was shown that the highest value is given by the reference sample without coconut fibre. The value is $2233 \mathrm{~kg} \mathrm{~m}^{-3}$ whereas the lowest value is given by the composite reinforced with $15 \mathrm{wt} \%$ of coconut fibre which is about $1875 \mathrm{~kg} \mathrm{~m}^{-3}$.

Density values of the composites after 28 days of curing still indicating similar trend of result as shown after 7 and 14 days of curing. The decreasing value of density with the addition of coconut fibre is shown in the result. The highest value of density $\left(2193 \mathrm{~kg} \mathrm{~m}^{-3}\right)$ is given by the reference sample without coconut fibre and the composite contains highest amount of coconut fibre has the lowest value of density which is $1845 \mathrm{~kg} \mathrm{~m}^{-3}$. From all of the density value for 7,14 and 28 days of curing, it shows that density value for 28 days of curing is more stable compared to 7 and 14 days of curing. Therefore, an analysis of decreasing trend was calculated for density value for 28 days of curing to make the difference value for each ratio were clearly seen. The density results obtained in this research are similar with the previous studies. Aggarwal (1995) in his research about bagassereinforced cement composite also reported that density values of cement composites decreased with increasing of bagasse content.

However, this result has contradicted with the researcher who studied the effect of palm oil fibre content in concrete. The results showed that density of the concretes with 0.25 and $0.50 \mathrm{vol} . \%$ of palm oil fibre higher than control sample without fibre (Subramani, 2007). But the difference in value of density for all the three different types of samples (control sample, sample with 0.25 and $0.50 \mathrm{vol} . \%$ of palm oil fibre) is just slightly different. The difference only in the range of $0-1 \%$ for both added fibre samples. The result between cement composite reinforced coconuts fibres with the concrete with palm oil fibre contradicted might because of the type of the fibre itself as palm oil fibre was heavier and can increase the weight of the sample while coconut fibre was lighter.

Crack profile of cement composite: The presence of crack in a composite may weaken it so that it fails by fracturing 
into $\geq 2$ pieces. The objective of studying about crack profile is to understand the correlation of cracks on every different sample with different amount of fibre content to the compressive strength. The crack profile of cement composite was observed after the samples have been tested under compression test. Figure 4a-f show compressed samples after 28 days of curing. The load applied to the sample was from the top of the samples.

Figure 4a shows the sample without coconut fibre has been totally failed because of the sample is brittle and there was no reinforced (fibre) to hold up the sample from fracture. This failure may decrease the value of compressive strength. Figure $4 \mathrm{~b}$ shows one of the five cement composites reinforced with 3 wt. $\%$ of coconut fibre after the compression. It can be seen that after undergoes compression test, the cement composite with 3 wt. $\%$ of coconut fibre content has cracked along the sample. The crack propagated from the point of load applied (top of the sample) to the bottom of the sample. It was found that the $3 \mathrm{wt} . \%$ of coconut fibre content did not enough to hold the cement composite from failure. Figure 4 has proved the reason of the average compression strength value for cement composite reinforced with 3 wt. \% coconut fibre value is lowered compared to the cement composites with 6 and $9 \mathrm{wt} . \%$ of coconut fibre. Figure $4 \mathrm{c}$ shows one of the five cement composites reinforced with 6 of coconut fibre after has been loading during compression test. By observing the type of crack profile from Fig. $4 \mathrm{c}$, it can be seen that cement composite with 6 wt. \% of coconut fibre has sheared from the point where load is applied to the centre of the sample. However, the sample did not break into piece when compared with the sample without fibre.

Figure $4 \mathrm{~d}$ shows the random cement composites samples which reinforced with 9 wt. $\%$ of coconut fibre after has been tested with the compression test. From Fig. 4, it can be seen that the crack stop at the centre of the sample after the load has been applied. According to Ismail, the addition of optimum value of fibre in cement composite can overcome their brittle behaviour that permitting a ductile behaviour in compression test. The fibre content in this cement composite has acted as a crack arrestor which creates a stage of slow crack propagation and gradual failure. It can be one of the reasons the compressive strength for cement composite reinforced with 9 wt. $\%$ of coconut fibre has the highest value. Figure $4 \mathrm{e}$ shows the cement composites reinforced with 12 wt. $\%$ of coconut fibre after has been loading with the compression test. For this sample, it can be observed that the crack occurred at the bottom of the sample. This could be happen because of the segregation
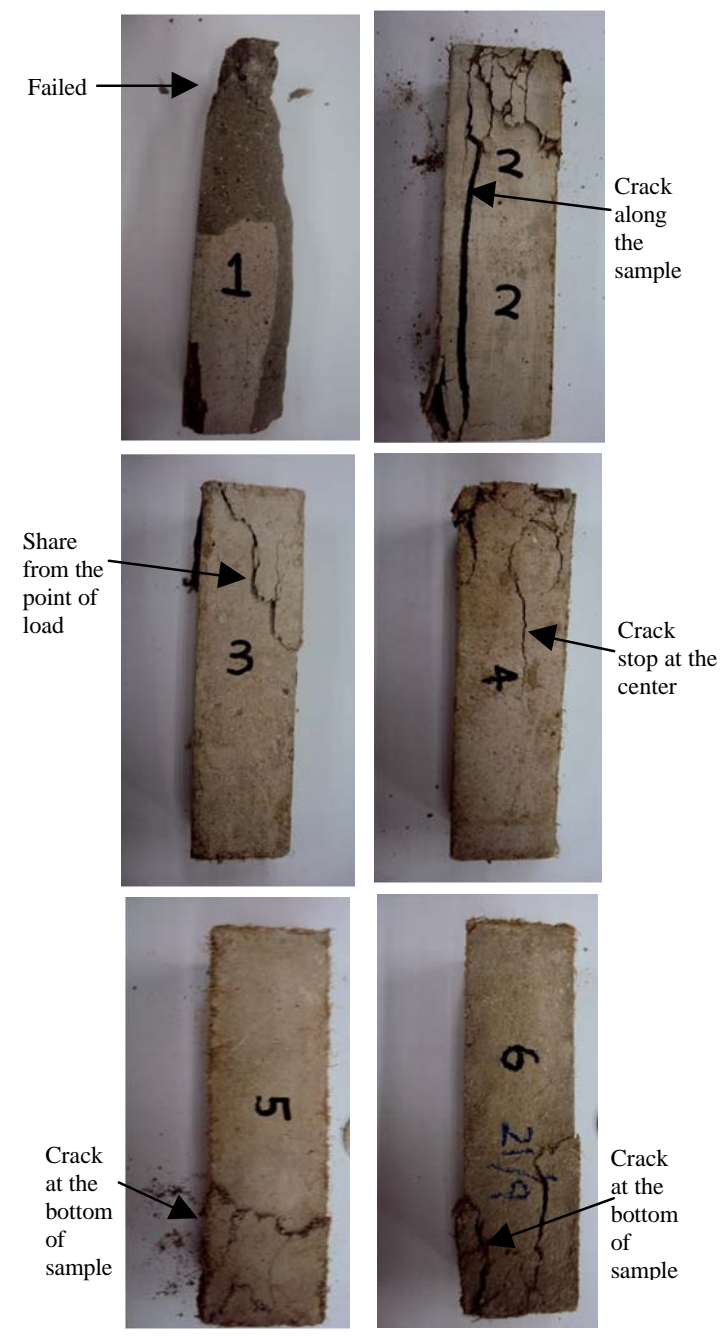

Fig. 4: The crack profile image of cement composites for entire ratios. Samples: a) without coconut fibre after compression test; b) Cement composite reinforced with 3 wt. \% of coconut fibre after compression test; c) Cement composite reinforced with 6 wt. $\%$ of coconut fibre after compression test; d) Cement composite reinforced with 9 wt. \% of coconut fibre after compression test; e) Cement composite reinforced with 12 wt. \% of coconut fibre after compression test and f) Cement composite reinforced with $15 \mathrm{wt} \%$ of coconut fibre after compression test

of fibre in the cement composite since, the amount of fibre content has exceeds its optimum value by referring to the value of compressive strength for this ratio. Figure $4 \mathrm{f}$ shows the cement composite reinforced with $15 \mathrm{wt}$. \% of coconut fibre after the compression test. Figure $4 \mathrm{f}$ shows 
the similar trend with Fig. 4e where the crack occurs at the bottom of the sample. From the observation, further addition of fibre content to the cement composite after exceeds the optimum value will make the length of crack at the sample increases and also contributes to the decreasing in compressive strength value.

\section{CONCLUSION}

From this research, it was found that the coconut fibre can be used as reinforcement and to substitute sand in the development of coconut fibre based-green composite. Increasing content of coconut fibre will increase the compressive strength of the composites until some optimum composition. In this research, the optimum mixing ratio for cement composite was composite with 9 wt. $\%$ of coconut fibre. Further increase in coconut fibre content in composite will decrease the strength due to non-workable mix design because of lack of water. Increasing in fibre content will decrease density of the composite. As for the crack profile, it was observed that the most less crack was for the sample with 9 wt. \% of coconut fibre whereas composite without fibre showed the sample failed as the load were applied to sample.

\section{ACKNOWLEDGEMENTS}

The researchers thank to the Ministry of Agriculture and Agro-Based Industry, Malaysia for providing the Research Grant and University Malaysia Perlis for the facilities provided for this research.

\section{REFERENCES}

Aggarwal, L.K., 1995. Bagasse-reinforced cement composites. Cement Concr. Compos., 17: 101-112.
Ahmad, M.H. and M.N. Nurazuwa, 2008. Mix design of palm oil fiber concrete. Proceedings of the International Conference on Civil Engineering, May 12-14, 2008, Kuantan, Pahang, Malaysia.

Asasutjarit, C., J. Hirunlabh, J. Khedari, S. Charoenvai, B. Zeghmati and U.C. Shin, 2007. Development of coconut coir-based lightweight cement board. Const. Build. Mater., 21: 277-288.

Asasutjarit, C., S. Charoenvai, J. Hirunlabh and J. Khedari, 2009. Materials and mechanical properties of pretreated coir-based green composites. Compos. Part B: Eng., 40: 633-637.

Askeland, D.R. and P.P. Phule, 2006. The Science and Engineering of Materials. 5th Edn., Cengage Learning Inc., UK., ISBN-13: 9780534553968, Pages: 863.

Hashim, M.H.B.M., 2005. Coconut fiber reinforced wall panelling system. Universiti Teknologi Malaysia, Malaysia, pp: 145. http:// www.efka.utm.my/ thesis/images/3PSM/2005/1 JSB/Part2/mohdhisban yma031111d05ttt.pdf.

Khedari, J., B. Sottisok, N. Pratinthong and J. Hirunlabh, 2001. New lightweight composite construction materials with low thermal conductivity. Cem. Concr. Compos., 32: 65-70.

Khedari, J., P. Watsanasathaporn and J. Hirunlabh, 2005. Development of fibre-based soil-cement block with low thermal conductivity. Cem. Concr. Compos., 27: 111-116.

Palomar, R.N., L.J. Penamora and A.E. Go, 1997. Utilization of coconut husk fibers and other cellulosic materials for the production of cement-bonded panels. Proceedings of the Regional Research and Development Symposium, July 23, 1997, New Astoria Hotel, Zamboanga City, Philippines.

Subramani, M., 2007. Palm oil fiber as an additive in concrete. Universiti Teknologi Malaysia, Malaysia. 